УДК 159.99 (075.8)

Синюк Диана Эдвардовна кандидат психологических наук, доцент, доцент кафедры психологии

УО «Брестский государственный университет имени А.С. Пушкина», г. Брест, Беларусь http://orcid.org/0000-0002-2362-9544

DOI https://doi.org/10.35619/prap_rv.vi14.170

\title{
ВЗАИМОСВЯЗЬ СТИЛЕЙ СЕМЕЙНОГО ВОСПИТАНИЯ СТАРШЕКЛАССНИКОВ И ИХ ГЕНДЕРНЫХ ПРЕДСТАВЛЕНИЙ
}

\begin{abstract}
Аннотация. В статье обсуждается роль семьи в формировании гендерных представлений старшеклассников. Определено, что гендерные представления - это обусловленные социумом понятия, взгляды, утверждения и объяснения относительно распределения ролей и статусных позиций мужчин и женшин в обществе. Установлено, что среди юношей и девушек, участвующих в исследовании, преобладают лица с андрогинным типом личности, так как у них маскулинные и феминные черты представлены гармонично и взаимодополняемо. Определено, что у большинства старшеклассников выявлены эгалитарные гендерные представления, а у их родителей значимо чаще обнаруживаются традиционные гендерные представления. Эмпирически доказано, что старшеклассники, родители которых используют авторитетный стиль воспитания, значимо чаще характеризуются эгалитарныли гендерныли представлениями. Старшеклассники, родители которых используют авторитарный и индифферентный стили воспитания, как правило, характеризуются традиционными или неопределенными гендерными представлениями. Установлено, что чем прогрессивнее гендерные представления у родителей, тем гармоничнее предпочитаемые ими стили семейного воспитания. Полученные данные могут использоваться педагогами-психологами учреждений образования в диагностических, прогностических $u$
\end{abstract} развивающих иелях.

Ключевые слова: гендерная идентичность, гендерные представления, гендерная соичиализация, андрогинность, маскулинность, феминность, психологический пол, стили семейного воспитания.

Постановка проблемы. Настоящее время характеризуется изменением традиционной системы половых ролей и соответствующих им стереотипов поведения, что, возможно, у некоторых людей, привыкших ориентироваться на однозначную и понятную для них норму, вызывает тревогу либо дискомфорт. В современном обществе виды деятельности уже не имеют столь четкой дифференциации на мужские и женские, взаимоотношения между мужчинами и женщинами в различных сферах жизнедеятельности стали более равноправными. Сложившиеся тенденции приводят к переменам в стереотипах маскулинности и феминности.

Общеизвестно, что на то, как именно человек отождествляет себя в социуме, влияет среда, в которой он рос и воспитывался. А первый опыт идентификации со своим полом происходит именно в семье, которая является важнейшим институтом социализации, в том числе, и гендерной. Поэтому в процессе нашего исследования мы попытались уточнить роль семьи в формировании гендерных представлений старшеклассников.

Анализ последних исследований проблемы. Под гендерной социализацией понимается процесс усвоения норм, правил поведения, установок в соответствии с социокультурными представлениями о роли, положении и предназначении мужчины и женщины в обществе (Красова, 2002).

Взрослые, ориентируясь на биологические признаки новорожденного ребенка, стремятся его воспитывать как мальчика или девочку, в соответствии с культурными традициями общества. При этом ученые выделяют ряд механизмов полового воспитания. В теории идентификации отмечается, что ребенок, подражая близким взрослым, бессознательно имитирует поведение родителей своего пола (Эриксон, 2000). В концепции гендерной типизации основное значение 
отводится механизмам подкрепления. Так, значимые взрослые хвалят девочек за «женственное», феминное поведение, мальчиков - за «мужественное», маскулинное поведение и, наоборот, осуждают, наказывают детей, когда их поступки выходят за рамки традиционных ожиданий. Мишель рассмотренный механизм назвал дифференциальным усилением. Также этот ученый описал еще один механизм - дифференциальное подражание. Данный механизм проявляется в том, что ребенок имитирует полоролевые модели поведения референтных социальных групп. В теории самокатегоризации утверждается, что сначала ребенок усваивает представления о том, что значит быть мужчиной или женщиной. Затем под влиянием взрослых он в процессе развития самосознания категоризирует себя как мальчика или девочку и стремится вести себя соответственно (Кулагина, Колюцкий, 2001).

Рассмотрим этапы становления гендерной идентичности. С. Томпсон описывает три стадии: сначала ребенок узнает, что существуют два пола; затем он относит себя к одному из полов; ребенок управляет своим поведением, ориентируясь на представления о себе как о мальчике или девочке (Ильин, 2000). Берн (2004) выделяет четыре этапа становления половой идентичности:

1) на первом этапе ребенок относит себя к мужскому или женскому полу, т. е. осуществляется его гендерная идентификация;

2) со временем ребенок начинает понимать, что гендер является постоянной характеристикой. Данный этап обозначается как гендерная константность;

3) у ребенка формируется желание быть самым лучшим мальчиком или девочкой дифференциальное подражание;

4) ребенок старается управлять своим поведением, стремясь вести себя как мальчик или девочка, применяя к самому себе определенные санкции. Этот этап обозначается гендерной саморегуляцией.

По мнению Кона (2003), первичная половая идентичность как стержневой элемент самосознания формируется у детей уже к полутора годам. В два года нормально развивающийся ребенок безошибочно называет свой пол, но при этом еще не умеет обосновать свои знания. В начале дошкольного возраста дети уже четко определяют пол людей, которые их окружают. К концу дошкольного возраста дети понимают необратимость половой принадлежности, осознают половые различия, на данном возрастном этапе у них усиливается половая дифференциация поведения и установок. Тельнюк (1999) также отмечает, что половая идентификация к 6 - 7 годам сформирована практически у всех детей. Однако они, прежде всего, обращают внимание на внешние половые признаки. А более существенные половые признаки (например, специфичные для мальчиков и девочек черты характера, предпочитаемые ими виды деятельности и др.) чаще всего старшие дошкольники еще не осознают. Следует отметить, что завершение формирования гендерной идентичности происходит, по мнению ученых, лишь в юношеском возрасте. А некоторые специалисты окончание становления гендерной идентичности отодвигают еще дальше.

Важным аспектом гендерной идентичности являются гендерные представления. При изучении литературы по проблеме исследования мы выяснили, что гендерные представления представляют собой обусловленные социумом понятия, взгляды, утверждения и объяснения относительно распределения ролей и статусных позиций мужчин и женщин в обществе. Существующие два основных типа гендерной идеологии (традиционная и эгалитарная), соответственно, отражаются и в гендерных представлениях. В основу традиционных гендерных представлений положен принцип жесткой дифференциации мужских и женских ролей, так как объективно существуют биологические половые различия. При этом утверждается, что именно мужчины должны занимать лидирующие позиции в обществе, так как по сравнению с женщинами в личностном плане они более совершенны.

Согласно эгалитарным гендерным представлениям, предполагающим равные возможности для личностной и профессиональной самореализации мужчин и женщин в разных сферах жизнедеятельности, они, как представители социальных групп, несмотря на половые различия, во многом похожи. Поэтому социальные роли мужчин и женщин взаимозаменяемы. Утверждается, что существующая гендерная дифференциация и поляризация является не биологически предопределенной, а социально сконструированной. 
Цель статьи - выявить взаимосвязь гендерных представлений и стилей семейного воспитания старшеклассников.

Изложение основного материала исследования. Для определения гендерных представлений старшеклассников и их родителей применялись следующие методики: «Полоролевой опросник» (Бэм), опросник «Пословицы» (Клецина). Для определения стилей семейного воспитания, характерных для родителей старшеклассников, использовался опросник «Стратегии семейного воспитания» (Хоу). В исследовании приняло участие 50 старшеклассников в возрасте 16-17 лет, а также их родители.

В первую очередь, рассмотрим психологический пол личности старшеклассников (см. таблицу 1).

Таблица 1

Психологический пол юночей и девущек

\begin{tabular}{|l|c|c|c|c|c|c|}
\hline \multirow{2}{*}{$\begin{array}{c}\text { Биологический } \\
\text { пол }\end{array}$} & \multicolumn{6}{|c|}{ Психологический пол } \\
\cline { 2 - 7 } & \multicolumn{2}{|c|}{ андрогиный } & \multicolumn{2}{|c|}{ феминный } & \multicolumn{2}{c|}{ маскулиный } \\
\cline { 2 - 7 } & $\begin{array}{c}\text { абсолютная } \\
\text { величина }\end{array}$ & в \% & $\begin{array}{c}\text { абсолютная } \\
\text { величина }\end{array}$ & в \% & $\begin{array}{c}\text { абсолютная } \\
\text { величина }\end{array}$ & в \% \\
\hline девушки & 14 & 54 & 7 & 27 & 5 & 19 \\
\hline юноши & 13 & 54 & 5 & 21 & 6 & 25 \\
\hline
\end{tabular}

Как следует из данной таблицы, более чем у половины девушек (54 \%) выявлен андрогинный психологический пол, характерной особенностью которого является сочетание в себе проявления как мужских, так и женских качеств. Примерно у четверти девушек $(27 \%)$ обнаружен феминный тип, в котором сочетаются такие качества, как уступчивость, мягкость, чувствительность, застенчивость, нежность, сердечность, способность к сочувствию, сопереживанию. Почти у пятой части респонденток (19\%) выявлен маскулинный пол личности, типичными чертами которого традиционно являются независимость, напористость, доминантность, агрессивность, склонность к риску, самостоятельность, уверенность в себе. В выборке девушек недифференцированный психологический пол не обнаружен.

Более чем у половины юношей, участвующих в данном исследовании (54 \%), встречается сочетание как мужских, так и женских качеств (андрогинный пол личности). Четверть юношей характеризуется маскулинным типом. Примерно у пятой части юношей (21 \%) выявлен феминный психологический пол. У юношей так же, как и у девушек, недифференцированный психологический пол не выявлен.

Таким образом, в двух группах респондентов преобладают лица с андрогинным типом личности. В соответствии с существующими представлениями индивид не обязательно является носителем четко выраженной психологической маскулинности или фемининности. В личности могут быть на паритетных началах представлены существенные черты как маскулинного, так и фемининного типов. При этом предполагается, что у андрогина эти черты представлены гармонично и взаимодополняемо. Считается, что такая гармоничная интеграция маскулинных и фемининных черт повышает адаптивные возможности андрогинного типа.

Далее рассмотрим гендерные установки старшеклассников и их родителей. Результаты исследования гендерных установок двух групп опрошенных представлены на рисунке 1. В первую очередь, узнаем гендерные установки старшеклассников о распределении ролей в семье. Мы выяснили, что большинство обучающихся (70\%) предпочитают эгалитарный тип семьи, для которого характерно совместное распределение ролей без разделения их на «мужские» и «женские». Таким семьям присуща взаимозаменяемость супругов в домашних делах. Следовательно, у большинства старшеклассников выявлены эгалитарные гендерные представления. 


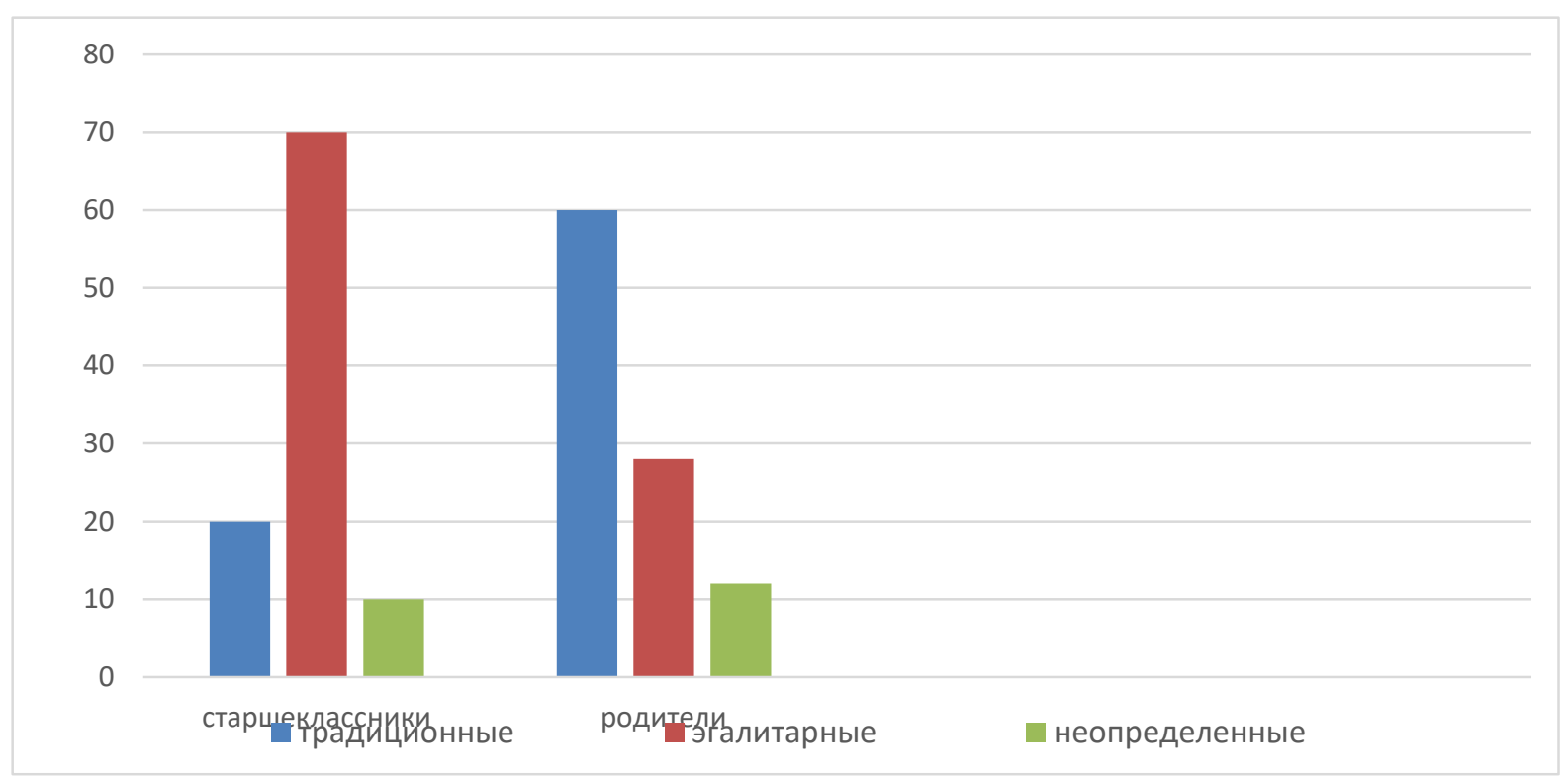

\section{Рис. 1. Гендерные установки старшеклассников и их родителей о распределении ролей в семье}

Пятая часть старшеклассников ориентирована на традиционную семью, в которой все домашние обязанности строго делятся на «мужские» и «женские» и большую часть этих обязанностей в современных семьях выполняет жена. При этом мы выяснили, что лишь десятая часть старшеклассников предпочитает неопределенный тип семьи, в котором не выражен типичный вариант распределения внутрисемейных ролей. Следовательно, их гендерные представления еще не сформированы.

Во вторую очередь, выясним, каково содержание гендерных установок родителей старшеклассников о распределении ролей в семье. Как следует из рисунка 1, у них чаще (в $60 \%$ случаев) встречаются традиционные гендерные представления, в 28 \% случаев - эгалитарные. Более чем у десятой части родителей выявлены неопределенные гендерные представления. Данный факт может свидетельствовать о том, что эти респонденты, прожив около 20 лет в браке, стали сомневаться в сложившихся у них представлениях о распределении ролей в семье.

Итак, мы выявили различия в предпочитаемых типах семей двумя поколениями. Применение критерия Фишера показало достоверность обнаруженных различий. Большинство старшеклассников, в отличие от своих родителей, выбирают эгалитарный тип семьи $\left(\varphi *_{\text {эмп }}=\mathbf{6 , 1 3 1}\right.$ при $\mathrm{p} \leq 0,01)$. Данные различия можно объяснить следующим. Современная тенденция к равноправию способствует размытию границ традиционного распределения обязанностей сугубо на «мужские» и «женские». Юноши и девушки стремятся в будущем создавать семьи с партнерскими отношениями. Результаты второй группы опрошенных свидетельствуют о предпочтении родителями, в отличие от их детей, традиционного института семьи $\left(\varphi *_{\text {эмп }}=\mathbf{5 , 9 7 5}\right.$ при $\mathrm{p} \leq 0,01)$. Межпоколенные различия можно объяснить особенностями воспитания и социализации детей и родителей в разной социальной среде.

Для определения предпочитаемых родителями стилей воспитания, проанализируем данные, полученные при проведении методики «Стратегии семейного воспитания». Мы выяснили, что чаще всего в ответах респондентов (у 52 \%) встречается выбор в пользу авторитетного стиля воспитания, который предполагает осознание родителями важности собственной роли в личностном развитии детей и уважение их права на саморазвитие. Данный стиль, по мнению специалистов, является наиболее благоприятным для становления личности детей, который способствует их успешной социализации. Подрастающий ребенок учится договариваться в семье, выстраивать отношения, основанные на доверии и взаимном уважении. При этом у него формируется осознанная дисциплина.

Более чем у четверти родителей (у 28 \%) обнаружен авторитарный стиль воспитания. Данный стиль включает в себя наличие представлений о том, каким должен вырасти ребенок. 
Родители предъявляют к детям высокие и необоснованные требования, ограничивают их самостоятельность, осуществляют жесткий контроль. При воспитании старшеклассников, у которых уже сформировано чувство взрослости, данный стиль воспитания, на наш взгляд, неприемлем, так как порождает многочисленные детско-родительские конфликты и формирует восприятие образа близких взрослых как врагов. Более независимые старшеклассники сопротивляются и бунтуют. Последствиями такого стиля воспитания являются робость, неуверенность, чувство внешнего контроля, которое основывается на чувстве вины или страха перед наказанием. Более десятой части родителей (12\%) характеризуются либеральным стилем воспитания. Данный стиль (гипоопека), несмотря на высокую ценность ребенка в глазах родителя и доверие, способен формировать у детей отсутствие критичности, которое в будущем может приводить к конфликтным ситуациям, когда юноша встретится с точкой зрения, отличной от его собственной. Также у молодых людей, воспитанных в либеральном стиле, могут возникать сложности в установлении эмоциональных связей. С другой стороны, воспринимая недостаток руководства со стороны родителей как проявление равнодушия и эмоционального отторжения, дети могут чувствовать страх и неуверенность. У незначительной части родителей $(8 \%)$ выявлен индифферентный стиль воспитания, который состоит в том, что для них проблемы воспитания не являются первостепенными. Поэтому проблемы ребенку приходится решать самому. По мнению специалистов, отсутствие участия и поддержки со стороны родителей могут сформировать у детей, воспитанных в индифферентном стиле, недоверие к миру.

На следующем этапе настоящего анализа рассмотрим сочетание психологического пола и гендерных представлений юношей и девушек (см. таблицы 2 и 3). Исходя из данных, представленных в таблице 2, более половины юношей характеризуются сочетанием андрогинного психологического пола и эгалитарных гендерных представлений. Данное сочетание, на наш взгляд, является наиболее благоприятным для жизни в обществе, так как гармоничная интеграция маскулинных и фемининных черт, а также их взаимодополняемость, повышает адаптивные возможности человека. Более десятой части юношей сочетают в себе маскулинный психологический пол, типичными чертами которого являются независимость, напористость, доминантность, агрессивность, склонность к риску, самостоятельность, уверенность в себе и, соответственно, традиционные гендерные представления.

Таблий 2.

Психологический пол и гендерные представления юночей

\begin{tabular}{|c|l|c|}
\hline Психологический пол & Гендерные представления & $\begin{array}{c}\text { Количество } \\
\text { юношей (в \%) }\end{array}$ \\
\hline андрогинный & эгалитарные & 54,17 \\
\hline маскулинный & традиционные & 12,5 \\
\hline маскулинный & неопределенные & 8,33 \\
\hline феминный & традиционные & 8,33 \\
\hline феминный & эгалитарные & 8,33 \\
\hline феминный & неопределенные & 4,17 \\
\hline маскулинный & эгалитарные & 4,17 \\
\hline
\end{tabular}

Менее десятой части респондентов мужского пола характеризуются сочетанием маскулинного психологического пола и неопределенных гендерных представлений. У такого же количества юношей выявлено сочетание феминного психологического пола и традиционных гендерных представлений, феминного психологического пола и эгалитарных гендерных представлений. Реже всего в выборке юношей представлено сочетание феминного психологического пола и неопределенных гендерных представлений, а также маскулинного психологического пола и эгалитарных гендерных представлений.

Випуск 14, 2020 Збірник наукових праць Р ДГУ. 
Проанализируем сочетание психологического пола и гендерных представлений девушек. Как следует из таблицы 3, менее половины респонденток характеризуются сочетанием андрогинного психологического пола и эгалитарных гендерных представлений. Практически пятая часть старшеклассниц являются носителями маскулинного психологического пола и эгалитарных гендерных представлений. У 15,38 \% респонденток выявлено сочетание феминного типа и эгалитарных гендерных представлений. У незначительной части девушек обнаружено сочетание феминного психологического пола и традиционных гендерных представлений, а также андрогинного психологического пола и традиционных гендерных представлений.

Таблииа 3.

Психологический пол и гендерные представления девушек

\begin{tabular}{|c|c|c|}
\hline Психологический пол & Гендерные представления & $\begin{array}{c}\text { Количество } \\
\text { Девушек (в \%) }\end{array}$ \\
\hline андрогинный & эгалитарные & 46,15 \\
\hline маскулинный & эгалитарные & 19,23 \\
\hline феминный & эгалитарные & 15,38 \\
\hline феминный & традиционные & 7,69 \\
\hline андрогинный & традиционные & 7,69 \\
\hline маскулинный & неопределенные & 3,85 \\
\hline
\end{tabular}

Реже всего у старшеклассниц встречается сочетание маскулинного психологического пола и неопределенных гендерных представлений. Таким образом, мы выяснили, что у юношей и девушек, участвующих в настоящем исследовании, доминирует сочетание андрогинного психологического пола и эгалитарных гендерных представлений. При сравнении полученных результатов мы выясняли связи между изучаемыми признаками с помощью коэффициента ранговой корреляции Спирмена (см. таблицу 4). В первую очередь, сравним гендерные представления родителей и стили семейного воспитания. Применение коэффициента ранговой корреляции Спирмена показало статистическую значимость корреляции между данными признаками, т. е. чем прогрессивнее гендерные представления у родителей, тем гармоничнее стиль семейного воспитания.

Далее сравним гендерные представления старшеклассников и стили родительского воспитания. Применение коэффициента ранговой корреляции Спирмена показало, что связь между данными признаками достигает уровня статистической значимости. Это свидетельствует о том, что старшеклассники, родители которых используют авторитетный (гармоничный) стиль воспитания, значимо чаще характеризуются эгалитарными (прогрессивными) гендерными представлениями.

Таблииа 4.

Значимость корреляционных связей между изучаемыми признаками

\begin{tabular}{|c|c|}
\hline Сравниваемые показатели & $\begin{array}{c}\text { Коэффициент ранговой корреляции } \\
\text { Спирмена }\left(\mathbf{r}_{s}\right) \\
\end{array}$ \\
\hline $\begin{array}{l}\text { гендерные представления родителей / стиль } \\
\text { воспитания }\end{array}$ & $0.631 * *$ \\
\hline $\begin{array}{l}\text { гендерные представления детей / стиль семейного } \\
\text { воспитания }\end{array}$ & $0.382 * *$ \\
\hline психологический пол / стиль семейного воспитания & $0.543 * *$ \\
\hline
\end{tabular}

Примечание: знаком «*» в таблице обозначены уровень статистической значимости : ** $-\mathrm{p} \leq 0,01(0,35)$ 
При этом старшеклассники, родители которых используют негармоничные стили воспитания, как правило, характеризуются традиционными или неопределенными гендерными представлениями. Таким образом, прослеживается очевидная связь между стилями семейного воспитания, используемыми родителями старшеклассников, и гендерными представлениями их детей. Полученные эмпирические данные подтверждают раннее высказанную теоретическую идею о том, что стили родительского воспитания взаимосвязаны с гендерными представлениям детей. При этом мы выяснили гармоничные и дисгармоничные сочетания гендерных представлений и стилей семейного воспитания. К наиболее гармоничному сочетанию мы относим эгалитарные гендерные представления и авторитетный стиль воспитания. К дисгармоничным сочетаниям, на наш взгляд, относятся индифферентные гендерные представления и неопределенный стиль воспитания, а также традиционные гендерные представления и авторитарный стиль воспитания.

Выводы и перспективы дальнейших исследований. Таким образом, проведенное исследование показало, что среди обследованных юношей и девушек преобладают лица с андрогинным типом личности. Установлено, что у большинства старшеклассников сформированы эгалитарные гендерные представления, a у их родителей значимо чаще обнаруживаются традиционные гендерные представления. Выявленные различия в содержании гендерных представлений двух выборок могут служить основаниями для возникновения конфликтов в детско-родительских отношениях. Следовательно, знание психологами гендерных представлений клиентов позволяет грамотно выстраивать взаимодействие с ними и оказывать адресную помощь.

Определено, что более половины родителей старшеклассников предпочитают авторитетный стиль воспитания, предполагающий осознание взрослыми важности собственной роли в становлении личности ребенка и уважение его права на саморазвитие. Более чем четверть родителей характеризуется предпочтением авторитарного стиля воспитания. Более десятой части родителей используют либеральный стиль воспитания. У незначительной части близких взрослых выявлено предпочтение индифферентного стиля воспитания, так как проблемы воспитания не являются для них первостепенными. Эмпирически доказано, что старшеклассники, родители которых используют авторитетный стиль воспитания, значимо чаще характеризуются эгалитарными гендерными представлениями. Старшеклассники, родители которых используют негармоничные стили воспитания, как правило, характеризуются традиционными или неопределенными гендерными представлениями. При этом установлено, что чем прогрессивнее гендерные представления у родителей, тем гармоничнее предпочитаемые ими стили семейного воспитания.

Перспективы дальнейшего исследования состоят в изучении роли других институтов социализации в формировании гендерных представлений современных юношей и девушек.

\section{СПИСОК ССЫЛОК}

Берн, Ш. (2004). Гендерная психология. Санкт-Петербург: Прайм-Еврознак.

Ильин, Е. П. (2000). Дифференциильная психофизиология мужчины и женщин. СанктПетербург: Питер.

Кон, И. С. (2003). Ребенок и общество. Москва: Академия.

Красова, Е. Ю. (2002). Полоролевая сочиализация. Москва: Информация XXI век.

Кулагина, И. Ю., Колюцкий, В. Н. (2001). Возрастная психология: полный жизненныий изикл развития человека. Москва: ТЦ «Сфера».

Тельнюк, И. В. (1999). Индивидуально-дифференцированньй подход $к$ организации самостоятельной деятельности девочек и мальчиков 5 - 6 лет в детском саду. (Дис. кандидата пед. наук). Санкт-Петербург.

Эриксон, Э. (2000). Детство и общество. Санкт-Петербург: ИТД «Летний сад». 


\title{
REFERENCES
}

Bern, Sh. (2004). Gendernaja psihologija [Gender psychology]. Sankt-Peterburg: PrajmEvroznak. [in Russian].

Il'in, E. P. (2000). Differencial'naja psihofiziologija muzhchiny $i$ zhenshhiny [Differential psychophysiology of men and women]. Sankt-Peterburg: Piter. [in Russian].

Kon, I. S. (2003). Rebenok i obshhestvo [Child and society]. Moskva: Akademija. [in Russian].

Krasova, E. Ju. (2002). Polorolevaja socializacija [Sex role socialization]. Moskva: Informacija XXI vek. [in Russian].

Kulagina, I. Ju., Koljuckij, V. N. (2001). Vozrastnaja psihologija: polnyj zhiznennyj cikl razvitija cheloveka [Age Psychology: The Complete Life Cycle of Human Development]. Moskva: TC «Sfera». [in Russian].

Tel'njuk, I. V. (1999). Individual'no-differencirovannyj podhod $k$ organizacii samostojatel'noj dejatel'nosti devochek $i$ mal'chikov 5 - 6 let $v$ detskom sadu [Individually-differentiated approach to the organization of independent activities of 5-6 year old girls and boys in the kindergarten]. (dis. kandidata ped. nauk). Sankt-Peterburg. [in Russian].

Jerikson, Je. (2000). Detstvo i obshhestvo [Childhood and society]. Sankt-Peterburg: ITD «Letnij sad». [in Russian].

\section{ВЗАСМОЗВ'ЯЗОК СТИЛІВ СІМЕЙНОГО ВИХОВАННЯ СТАРШОКЛАСНИКІВ ТА ЇХ ГЕНДЕРНИХ УЯВЛЕНЬ}

\author{
Діана Синюк \\ кандидат психологічних наук, доцент, \\ доцент кафедри психології \\ Брестського державного університету \\ імені О. С. Пушкіна, м. Брест (Республіка Білорусь) \\ http://orcid.org/0000-0002-2362-9544 \\ DOI https://doi.org/10.35619/prap_rv.vi14.170
}

\begin{abstract}
Анотація. У статті обговорюється роль сім'ї у формуванні гендерних уявлень старшокласників. Визначено, щз гендерні уявлення - це обумовлені сочіумом поняття, погляди, твердження $i$ міркування щуодо розподілу ролей $i$ статусних позичій чоловіків $i$ жінок в суспільстві. Доводиться, що у юнаків та дівчат, які брали участь в дослідженні, переважають особи з андрогінним типом особистості, оскільки маскулінні і фемінні риси у них представлені гармонійно та взаємоузгоджено. Визначено, щу у більшості старшокласників виявлені егалітарні гендерні уявлення, а у їхніх батьків - традиційні.

Емпірично доведено, щзо для старшокласників, батьки яких використовують авторитетний стиль виховання, типовими є егалітарні гендерні уявлення. Старшокласники, батьки яких використовують авторитарний $і$ індиферентний стилі виховання, переважно, характеризуються традииійними або невизначеними гендерними уявленнями. Встановлено, щэо чим прогресивніші гендерні уявлення батьків, тим більш гармонійним стилям сімейного виховання вони віддають перевагу.

Отримані дані можуть використовуватися педагогами-психологами установ освіти в діагностичних, прогностичних і розвиваючих иілях.
\end{abstract}

Ключові слова: гендерна ідентичність, гендерні уявлення, гендерна соиіалізація, андрогінність, маскулінність, фемінність, психологічна стать, стилі сімейного виховання

Diana Siniuk,

Candidate of Psychological Sciences, Associate Professor at the Department of Psychology Brest State A.S. Pushkin University, Brest, Belarus 0000-0002-2362-9544 


\title{
INTERRELATIONSHIP BETWEEN THE PARENTING STYLES AND THE GENDER ATTITUDES OF HIGH SCHOOL STUDENTS
}

\begin{abstract}
The influence of family on the establishing of gender attitudes of high school students is discussed in the article. It is stated that development of gender representations, in terms of concepts,points of view, experiences, thoughts regarding the distribution of social roles and positions of men and women in the society, take place under the strong influence of social rules. Obtained resuls showed that among the boys and girls, participating in the study, individuals with an androgynous personality type predominated, since their masculine and feminine features were presented harmoniously and complementarily. It was found that the majority of high school students had egalitarian gender perceptions, which suggest equal opportunities for personal and professional self-realization of men and women in different spheres of life. Students believed that despite gender differences, they, as representatives of social groups, are very similar. Therefore, the social roles of men and women are interchangeable. At the same time, parents of high school students were significantly more likely to follow traditional gender rules. Such gender ideas are based on the principle of strict differentiation of male and female roles, due to the existing of objective biological sex differences. Further, we examined combination of students gender types and their attitudes regarding the social roles of men and women. We found that the majority of participants had an androgynous type of gender combined with egalitarian gender attitudes.

It has been empirically proven that high school students whose parents use an authoritative parenting style were significantly more often characterized by egalitarian gender perceptions. Young people, whose parents use authoritarian and indifferent parenting styles had proneness to follow traditional or indefenite gender perceptions. We also found the close relationship between the parents' gender attitudes and their style of parenting: the more progressive the parents' attitudes were, the more harmonious preferred styles they had.
\end{abstract}

Key words: gender identity, gender representations, gender socialization, androgyny, masculinity, femininity, parenting style. 